\title{
A NEW CONTINUOUS POLLEN SAMPLER ${ }^{1}$
}

\author{
P. W. VOISEY ${ }^{2}$ AND I. J. BASSETT \\ Canada Department of Agriculture, Ottawa, Ontario
}

[Received for publication July 10, 1961]

\begin{abstract}
A new continuous volumetric pollen sampler is described which eliminates considerable labour when studying diurnal variations for long periods. Preliminary results using this new apparatus at Ottawa in late August and September showed definite hour-to-hour Ambrosia pollen variations with peaks up to nearly 400 pollen per cubic yard of air occurring in the early morning.
\end{abstract}

\section{INTRODUCTION}

Considerable information has been gathered in the last few years $(2,3)$ on the present distribution of ragweeds, Ambrosia spp., in Canada by field and air-borne pollen surveys across the country. The standard gravity type of collecting apparatus (Durham apparatus) as recommended by the pollen survey committee of the American Academy of Allergy (1) has been widely used in these surveys of air-borne pollen. With this apparatus slides are exposed for 24-hour periods.

To obtain further information from any given locality over a long period at more frequent intervals on the distribution and abundance of airborne pollen and to investigate correlations between environmental factors and pollen incidence a more efficient type of collecting apparatus is required. In this paper a new continuous volumetric pollen sampler designed to meet these requirements is described; preliminary results with Ambrosia pollen using this new sampler are also reported.

Several types of pollen-collecting apparatus have been described in the literature and their evaluation and efficiencies have been discussed $(5,9)$. However, there is little published information on the abundance and types of air-borne pollen encountered using one of the more highly efficient samplers such as the rotobar. In order to conduct hourly pollen dispersal studies with the rotobar apparatus over long periods of time, considerable manual labour would be required.

Smith and Rooks (11) were successful in studying hourly variations of ragweed pollen at Iowa City, Iowa, during August and September, 1952, using a continuous recording volumetric particle sampler previously described by Stenburg and Hall (12). Hyde (7) was able to obtain much more air-borne pollen data in South Wales with the Hirst automatic volumetric spore trap (6) than with the standard gravity type of apparatus. By combining desirable features from several of these machines, including one recently described by Pady (10), and incorporating some modifications, the senior author has designed a new continuous volumetric pollen sampler. This apparatus, although made of inexpensive materials, required considerable detailed work and construction time.

\footnotetext{
${ }^{1}$ Contribution No. 15 from the Engineering Research Service, Contribution No. 156 from the Plant Research Institute, Research Branch, Canada Department of Agriculture, Ottawa, Ont.

'Engineering Research Service.

splant Research Institute.
} 


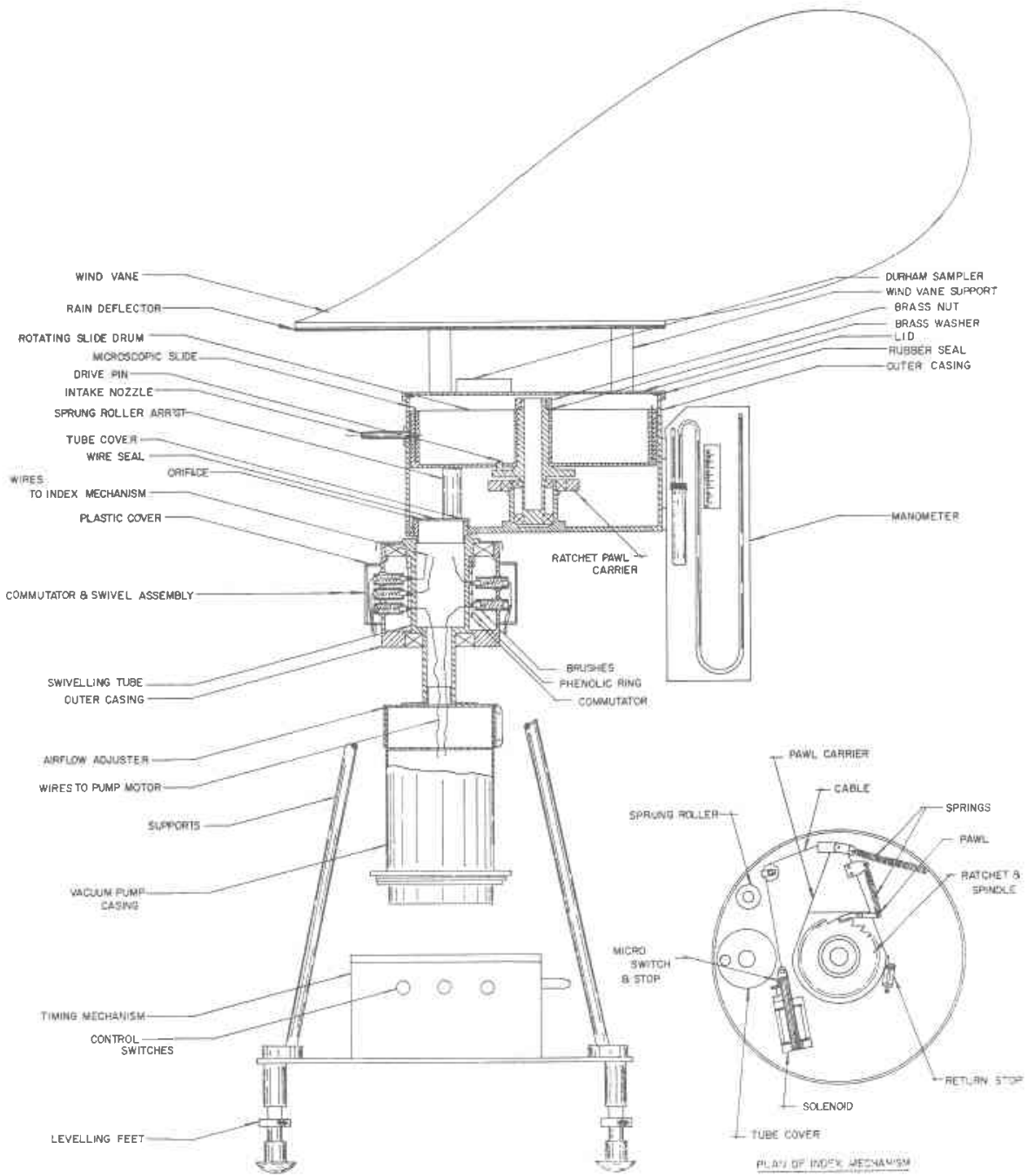

Figure 1. Sectioned elevation, continuous pollen sampler.

One of the chief advantages of this new sampler is that a drum can be loaded with 24 slides in the laboratory and then can be interchanged without loss of time or danger of contamination with the drum containing the exposed slides in the machine. Each slide is in a separate slot and is exposed for a definite period ( 15 minutes to 24 hours). This is a considerable advantage over other designs where the pollen is deposited on a single, slowly moving slide from which it is difficult to determine precisely how much has been trapped during a particular period of time. 

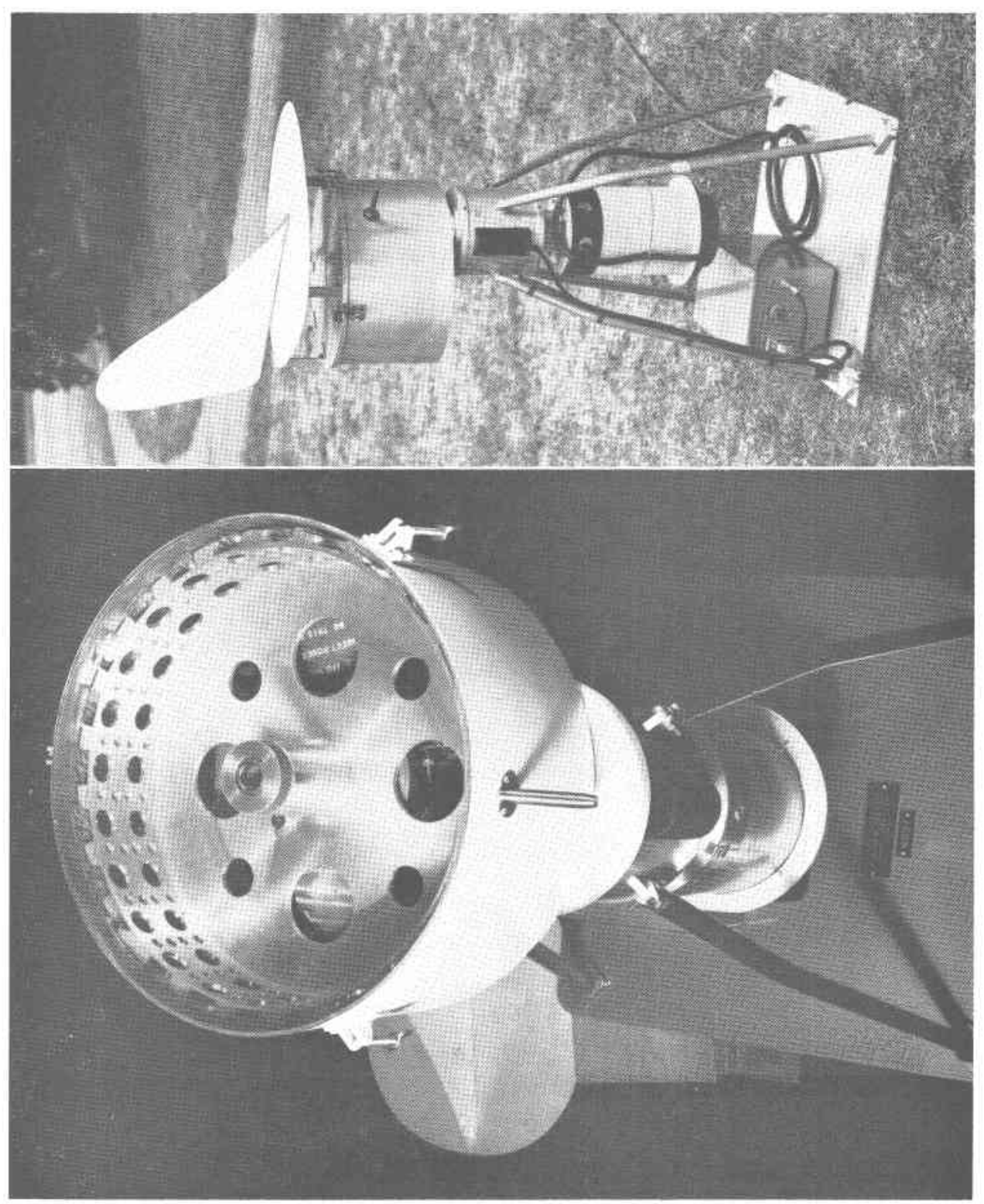

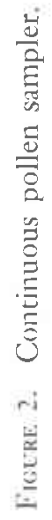


짐 


\section{Description of Apparatus}

The complete sampler is shown in Figures 1 and 2. The apparatus is self-contained, portable and will operate in any location where electric power is available. Utilizing standard 1 inch $\times 3$ inch microscope slides, coated with a thin layer of glycerine jelly to trap pollen admitted by a 0.25 -inch diameter nozzle 1 metre above the ground, the sampler operates as follows. (Figure 1 is a sectioned elevation). Slots around the periphery of an aluminum drum accommodate 24 slides. The drum is driven by a ratchet wheel integral with its spindle and rotates each time the indexing mechanism operates. The simple indexing mechanism is driven by a solenoid, while a sprung roller drops into a detent at each slide position, preventing continuous rotation and aligning the slide with the nozzle axis. Slide drum and indexing mechanism are mounted in an air-tight chamber attached to the top of a swivelling tube. A wind vane, rain shield and a standard gravity type slide holder are mounted on the lid assembly. The complete assembly is thus able to turn the nozzle into the prevailing wind. Air is drawn from the air-tight chamber by a vacuum cleaner motor and blower establishing flows up to 26 l.p.m. through the nozzle whose face is 1 millimetre from the slide. Flow is controlled by bypassing air to the pump and indicated by a calibrated manometer.

\section{Calibration and Design}

The nozzle length was arranged so that maximum streamline deviation at its entry was $5^{\circ}$ when considering flow around the outer case. This compromise was considered satisfactory, since pollen was not found to stick inside the polished stainless steel nozzle and the slides were coated fairly evenly over a 0.25 -inch diameter area.

The exposure of one slide for a period of 8 hours in front of the nozzle did not reveal any trace of dust or pollen on adjacent slides inside the drum. The movement of one slide to the next slot also did not result in any contamination on the unexposed slides inside the drum.

The efficiency of the apparatus was compared with that of a cascade impactor (8) using a similar technique to that of Gregory (4), who determined the trapping efficiency of cylinders. Insufficient data were obtained to give accurate efficiencies, since the large wind tunnel used was not suitable for the purpose. Sampling at 6.8 l.p.m. gave the best results at wind speeds between 4 and 12 m.p.h., i.e. the sampler operated isokinetically at 8 m.p.h.

\section{Pollen Results}

The new sampler was located at ground level at the agrometeorological station, Central Experimental Farm, Ottawa. In Figure 3, hour-to-hour variations in the amounts of Ambrosia pollen trapped are shown for August 23-24 and September 22-23, 1960. Similar results were obtained on August 29-30, as shown for August 23-24. The low pollen peaks on September 22-23 are probably due to the fact that the ragweeds had already passed their maximum flowering period. Weather conditions for each day 


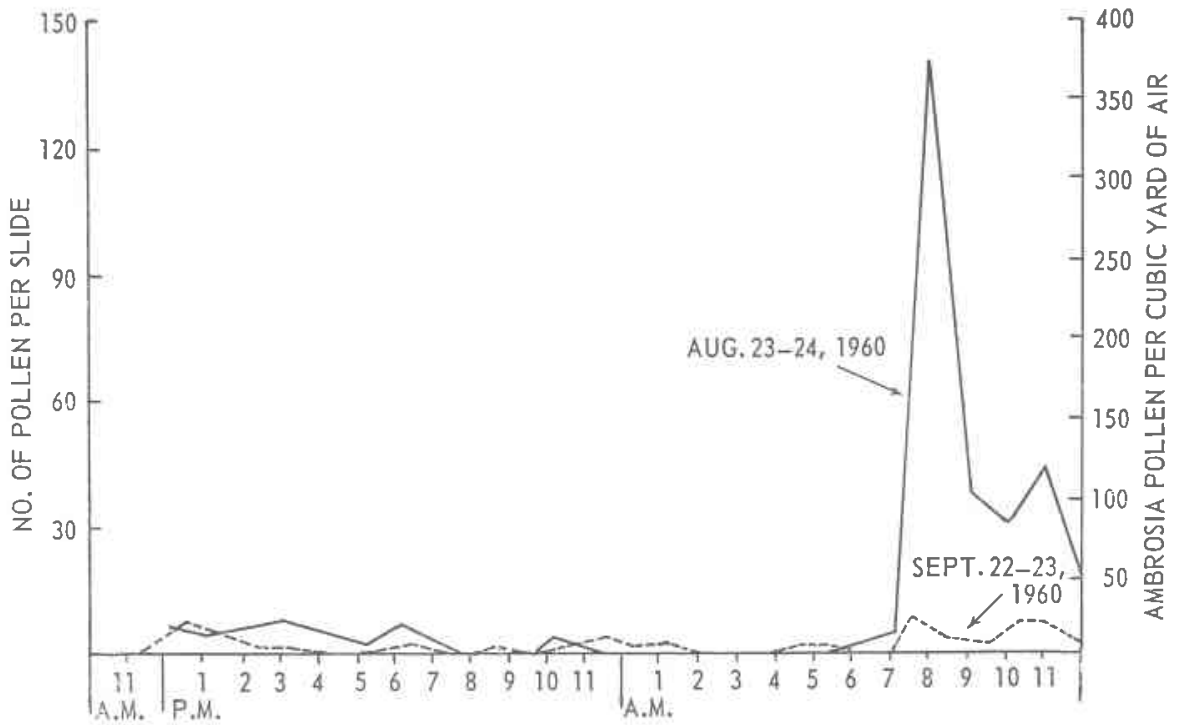

Figure 3. The number of Ambrosia pollen per hour collected on August 23-24 and September 22-23, 1960.

of operation were about normal for this area with temperatures above $68^{\circ} \mathrm{F}$., relative humidity over 65 per cent, light winds, sunny and cloudy periods, with no rainfall.

The peak pollen periods, in all cases, were in the early morning between 7 and 9 o'clock. After these peak periods there was a tapering-off during the rest of the day with very little Ambrosia pollen collected at night-time. Further studies are being continued to determine whether or not these preliminary results are typical. The number of pollen grains per cubic yard of air was calculated from the number of pollen per slide with the machine operating at a constant air-intake of 4.8 l.p.m.

Although the percentage efficiency of this new sampler was not obtained accurately, it is felt, from tests conducted, that its efficiency is similar to that of the Stenburg and Hall apparatus which was reported to be over 70 per cent.

\section{ACKNOWLEDGEMENTS}

The authors wish to thank D. C. MacPhail, Director, Division of Mechanical Engineering, National Research Council, for permission to use one of their wind tunnels for testing the new sampler and for the services rendered by his staff.

\section{REFERENCES}

1. American Academy of Allergy. Rept. Natl. Pollen Survey Comm. J. Allergy 17:178. 1946; 18:284. 1947.

2. Bassett, I. J. Surveys of air-borne ragweed pollen in Canada with particular reference to sites in Ontario. Can. J. Plant Sci. 39:491-497. 1959.

3. Bassett, I. J., and C. Frankton. Canadian havens from hay fever. 7th ed. Dept. Northern Affairs and Natl. Resources, Ottawa, Ont. 1961: 
4. Gregory, P. H. Deposition of air-borne Lycopodium spores on cylinders. Ann. Appl. Biol. 38:357-376. 1951.

5. Harrington, J. B., G. C. Gill, and B. R. Warr. High-efficiency pollen samplers for use in clinical allergy. J. Allergy 30:357-375. 1959.

6. Hirst, J. M. An automatic volumetric spore trap. Ann. Appl. Biol. 39:257-265. 1952.

7. Hyde, H. A. Volumetric counts of pollen grains at Cardiff, 1954-1957. J. Allergy 30:219-234. 1959 ,

8. May, K. R. The cascade impactor: An instrument for sampling coarse aerosols. J. Sci. Instruments 22:187-195. 1945.

9. Ogden, E. C., and G. S. Raynor. Field evaluation of ragweed pollen samplers. J. Allergy 31:307-316. 1960.

10. Pady, S. M. A continuous spore sampler. Phytopathology 49:757-760. 1959.

11. Smith, R. D., and R. Rooks. The diurnal variation of air-borne ragweed pollen as determined by a continuous recording particle sampler and implications of the study. J. Allergy 25:36-45. 1954.

12. Stenburg, R. L., and L. B. Hall. A continuous recording particle sampler. Proc. 5th meeting, Northeast Weed Control Conf., pp. 311-317. 1951. 